\title{
Research on Stability of Slope of landfill Site Based on FLAC ${ }^{3 D}$ Yifan Zeng ${ }^{\mathrm{a}}$,Shouqiang Liu $^{\mathrm{b}}$, Yanliang Zhai ${ }^{\mathrm{c}}$ and Wei Zhang ${ }^{\mathrm{d}}$ China University of Mining \& Technology, Beijing, Beijing 100083, China \\ azengyifan_1011@sina.com, bsqliu@cumtb.edu.cn, ${ }^{\mathrm{c}} 718092827 @ q q . c o m$, dzw19890616@gmail.com
}

Keywords: FLAC ${ }^{3 D}$; Stability of slope; Strength reduction method; Safety factor; Slope reinforcement

Abstract. The research is aiming to solve the slope stability problem for the landfill project of Ordos coal deep processing project conducted by Zhong Tian Energy Co., Ltd. It analyzes the stability and reinforcement measures for the slope of landfill via theoretical analysis and numerical simulation. The first step is to obtain the security coefficient by simulating and calculating the typical side slope using FLAC ${ }^{3 \mathrm{D}}$ strength reduction method. Then, it understands the failure mechanism of side slope is overall sliding and pull splitting by analyzing the offset, stress and shear strain increment of the side slope model. Therefore, paving geogrid to reinforce the side slope is proposed in the preliminary treatment plan according to actual situation.

\section{Introduction}

The stability of the industrial waste landfill slope has a significant impact on the entire site reliability, safety and socio-economic benefits. Landfill slope design is an important part of the project cost and safety, if the slope angle is small, landfill capacity will be reduced, resulting in economic losses. However, if the slope angle is too large, once landslides, slope instability dam failure and other accidents, landfill impermeable layer will be destroyed and industrial leachate will leak, it will not only pollute the surrounding environment, and after the occurrence of slope instability, under the impact force and gravity together, industrial landfill body may instability, causing a major disasters accidents of a large number of industrial waste landfill emission, resulting in serious pollution of the environment and endangering the lives of surrounding residents ${ }^{[1]}$. In addition, once large-scale landslide occurred and repair the landfill will be an enormous cost engineering, environmental restoration around the contaminated areas will be even more difficult governance. In view of this, it is necessary to understand and master the slope deformation and failure mechanisms as well as landfill slope stability analysis and evaluation.

In summary, in order to correct analyze the destruction of landfill slopes, we must track slope pull destruction, shear failure and strain softening process. For the above, this paper uses FLAC ${ }^{3 \mathrm{D}}$ program to simulate slope failure process of the Zhong Tian of the Ordos coal deep processing projects landfill project.

\section{The implementation process of the finite difference method of landfill slope}

In the FLAC ${ }^{3 \mathrm{D}}$, the engineering simulation of the soil embankment slope is based on the actual construction, implementing with the corresponding load unit step through "activating" the fill soil and reinforcement measures. Geotechnical engineering construction stage analysis is a cumulative model, which each construction stage of the analysis result is based on the basis of the construction stage, therefore, each stage only needs to add the relevant stage of the load and the unit ${ }^{[2]}$.

In spite of the construction process of practical engineering construction site of slope embankment is very complicated, this article focused on one of the important construction stages with the normal construction sequenceto simulate. And the implementation process of the FLAC ${ }^{3 \mathrm{D}}$ simulation of the fill soil embankment slope can be showed as follows:

(1) Set up the model of slope body and activate the slope soil foundation soil unit voundary conditions and the gravity load, and zero the displacement due to weight of soil. Retain the only initial ground stress and format the initial geostress field of slope foundation; 
(2)Activate the fill soil and geogrid unit, and activate the soil weight of load 、 the corresponding boundary conditions and the weight of fill soil;

(3)Repeat the step (2) until completing the filling of the fill soil and the laying of the reinforcement measures, establish the analyzed working condition (natural conditions、 rainfall conditions) of the filling soil embankment slope, analyze simulated calculation of the working condition ,and work out the cloud picture of the stress field、 displacement field and the shear strain increment after completing each construction stage as well as the cloud picture of the slope ultimate stress field、 displacement field and shear strain increment after the completion of the construction of the whole slope. Choose the form of graphics curve and table in the post-processing mode and output the analysis results according to the needs of engineering analysis.

\section{FLAC $^{3 \mathrm{D}}$ analysis of soil slope}

Using 3D finite difference method to carry on the numerical simulation of landfill fill slope computation and calculate the safety factor of the instability slope and analyze its under the weight of the slope deformation characteristic and its stability. Slope stability analysis type choose SRM strength subtraction.

\subsection{The scope and generalized computing model}

Analysis of the finite difference method, determine the scope of the reasonable analysis is extremely important. Analysis scope is too small or too metropolitan affect the accuracy of analysis, increasing the time is the best way to meet the accuracy requirement of simulation. According to the experience of the study, the lateral analysis width 6 times of landfill slope height, depth analysis for three times the height of slope ${ }^{[3]}$.

\subsection{The material parameters}

Reasonable selection of geotechnical parameters directly affect the proximity between the model analysis results and the actual situation.Numerical simulation analysis of slope engineering model of elastic modulus and poisson's ratio general consult experience data. On the basis of comprehensive comparative analysis, consulted related geotechnical engineering specification and similar engineering experience:general soil elastic modulus values were selected in accordance with the compression modulus of 2-5 times, Silt experience value of poisson's ratio were selected 0.23-0.31, compacted fill of poisson's ratio is generally chosen $0.35^{[4]}$.

\subsection{The establishment of calculation model}

\subsubsection{The fundamental assumption}

For convenience of analysis and research, the model was set up for the following assumptions: (1) Analyze the ideal soil, and calculate with the analysis of the total stress method; (2) Soil types adopt the plane strain model, and yield criterion adopt the Mohr-Coulomb criterion; (3) Calculate and analyze typical section, and ignore the contact problem between different layers; (4) Ignore the imposed load caused by the construction of slope soil additional stress; (5) planar contact between the layers of material ${ }^{[5]}$.

\subsubsection{Modeling and meshing process}

Slope stability calculation model is set up, filled soil, silt, sand and mudstone adopt plane strain model, quadrilateral grid type selection, the circular grid method is adopted, and select the reasonable size of automatic dividing plane grid, slope foot are local refinement. Meshing results as shown in figure 1 


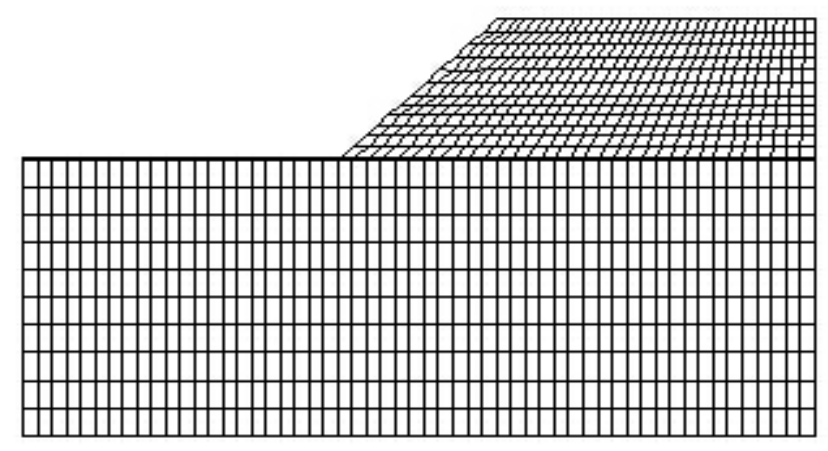

Fig.1 Meshes Model

\subsubsection{Boundary conditions and load conditions}

The model level constraints were imposed to the right or left side boundary, limit the soil lateral freedom, underside boundaries imposed under horizontal and vertical constraints, limit freedom of the horizontal and vertical soil layer.The loading charge is soil gravity load.

\subsection{Analysis of computing result}

\subsubsection{The constitutivemodel of filling slope and instability criterion}

The constitutive model of soil slope and the instability criterion of FLAC ${ }^{3 \mathrm{D}}$ include many kinds of constitutive models of elastic and plastic materials. Considering the filling slope of the landfill site is silt, sandy soil, etc. Selecting the Mohr-Coulomb constitutive model. The numerical simulation method is used to study the effect of gravity stress field, Landfill model slope caving process, calculate landfill slope safety factor ${ }^{[6-7]}$. Elastoplastic constitutive model, obey Mohr-Coulomb criterion in the following equation:

$$
f=\frac{1}{3} I_{1} \sin \varphi+\left|\cos \omega_{b}-\frac{1}{\sqrt{3}} \sin \omega_{b} \sin \varphi\right| \sqrt{J_{2}}-\cos \varphi=0 .
$$

Where $\mathrm{f}$ is material yield function (F greater than 0 , Material in the elastic state; $\mathrm{F}$ less than 0 , then the material in a plastic state); $\varphi$ is internal friction angle $\left({ }^{\circ}\right)$; c is cohesive force; $I_{1}$ is first stress tensor invariant; $J_{2}$ is second stress tensor invariant; $\omega_{b}$ is stress Rhodes angle $\left(^{\circ}\right)$.

Numerical simulation of slope instability criterion mainly has the following three: characteristic position shift mutation; convergence of numerical calculation; Plastic zone.

\subsubsection{Numerical simulation results analysis}

The horizontal displacement of the slope can be seen in figure 2, horizontal displacement concentration analysis of airport surface,the horizontal displacement is produced in the free surface of slope and it is large in the middle of free surface and toe soil.The maximum displacement of horizontal surface is $-2 \mathrm{~m}$, the minus sign indicates that the level of movement toward the left slope, indicating the slope is completely destroyed. According to the vertical direction, vertical displacement is larger when embankment soil is thicknessat the top of the slope, the range of vertical displacement at the top of the slope is $[(-1.8 \mathrm{~m}), 0]$. The negative displacement indicates that the vertical displacement of the slope occurs. The simulation results are consistent with the actual situation of the soil compaction under dead load.

From Figure 3, the maximum principal stress value appears in the most deep position of the slope. The distribution of principal stress contour which is strip is consistent with that of soil stratum. At the top and foot of the position,it occurs stress concentration, and it may damage.According to the minimum principal stress distribution of the section, the maximum values are also found in the deep of 
the slope. The minimum principal stress value of the top and foot position is tensile stress. They may occur tension crack because of tensile stress, and the slope local position may occur tensile failure.

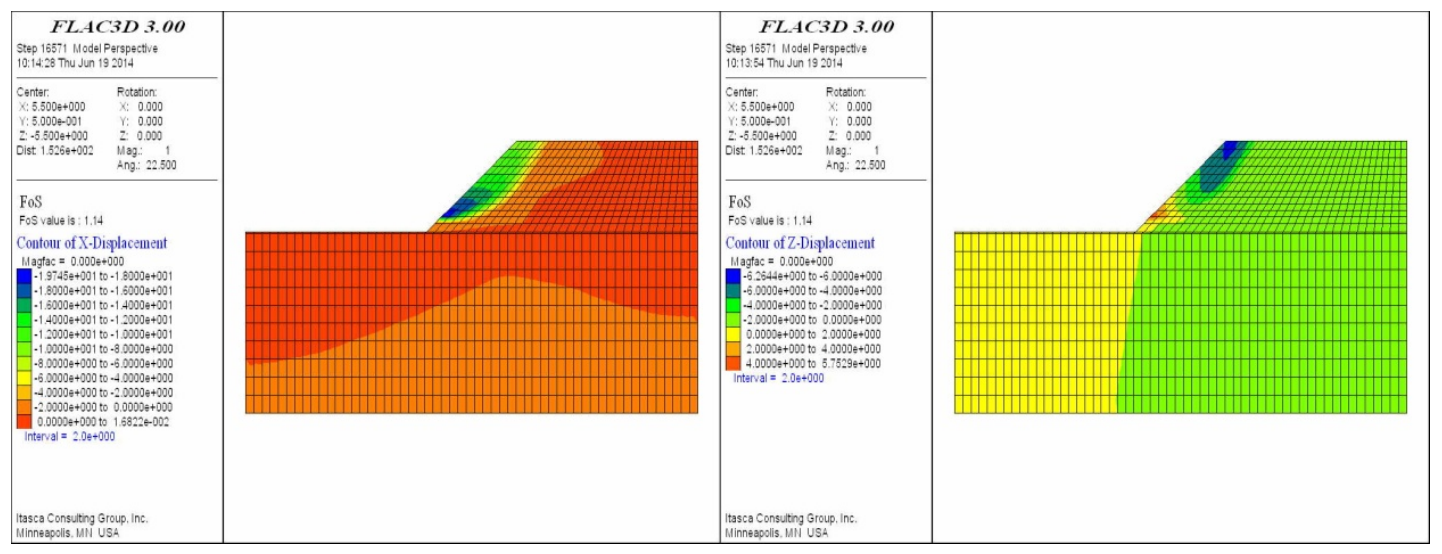

(a) Horizontal displacement

(b) Vertical displacement

Fig.2 Contour of Displacement

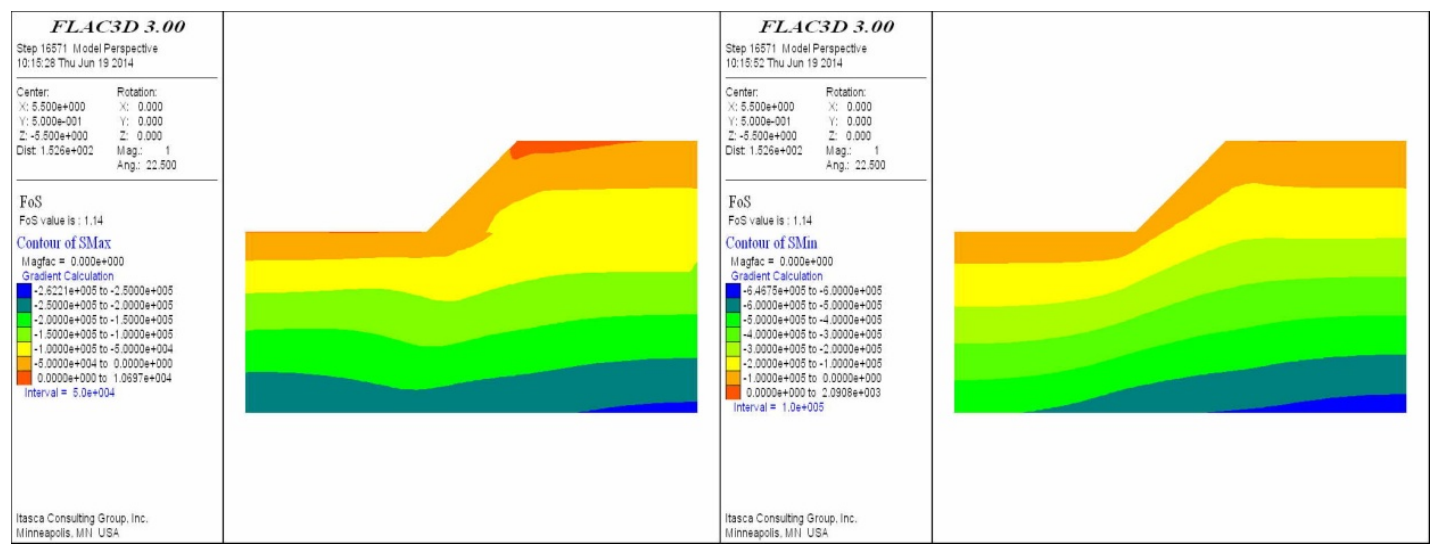

(a) The maximum principal stress distribution (b) The minimum principal stress distribution

Fig.3 ContourofPrincipal Stress

The distribution of shear strain increment slope model shown in Figure 4, according to Mohr-Coulomb criterion, added the geotechnical parameters into physical strength equation (1), local area $\mathrm{f}$ is less than 0 , so it is in a plastic state. As shownin Figure 4, the slope from the foot to the top of the hill plastic zone develops into a curved surface, and the thickness of it is about $6 \sim 10 \mathrm{~m}$, maximum shear strain increment development in the toe portion. Remaining area $\mathrm{f}$ is greater than 0 , it is still in elastic state. Slope failure occurred slip characteristics significantly, According to the plastic zone shape, we can see the slope along the circular surface damage occurs.

The results based on slope deformation finite difference method for modeling the slope obtained, and considering the slope shape, we can get the slope deformation and failure characteristics are mainly whole slope sliding - fracturing formula destruction. According to the finite difference method simulation, landfill slope safety factor $F s=1.14$, it is less than 1.3 , so it does not meet the "Construction Side Slope Engineering Technology Standard"(GB50330-2002) requirements. Therefore, it should be designed for slope stabilization measures under the slope deformation and failure characteristics and practical engineering. 


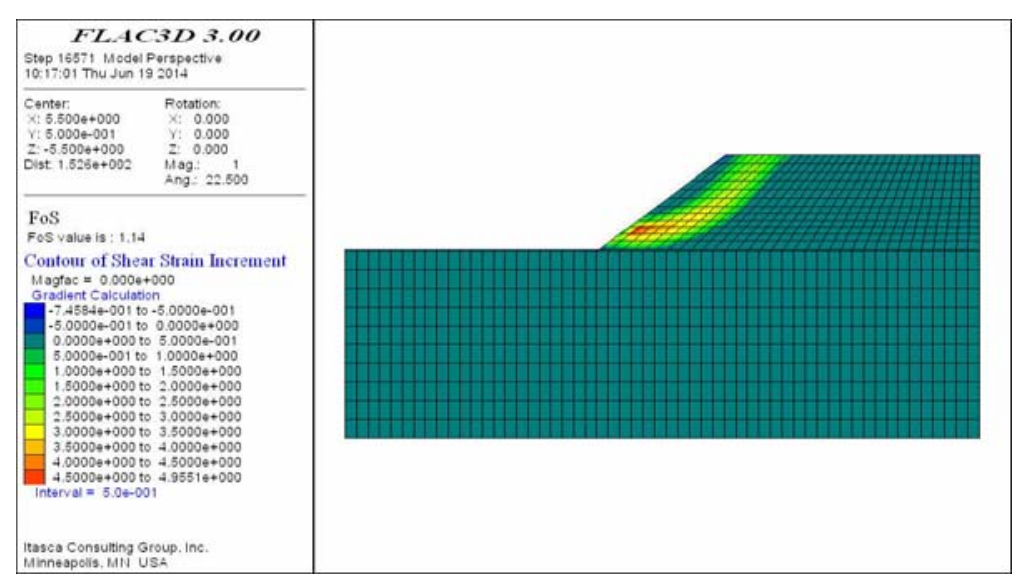

Fig.4 Contour Of Shear Strain Increment

\section{Conclusion}

(1) Making the simulation of the filled slope of landfill site engineering of the deep processing project of coal in Zhongtian of Ordos by FLAC ${ }^{3 \mathrm{D}}$, and thesimulation calculation shows that the safety factor (Fs) of the slope is 1.14, which is lower than requirements of "Construction Side Slope Engineering Technology Standard"(GB50330-2002). According to the analysis results of slope deformation simulated with finite difference method,considering the shape of slopesynthetically, it is obtained that deformation and failure characteristics of slope mainly including: the whole slopesliding and fracturing, a curved surface developed from the foot to the top of the slope as the slip surface, tensile failure occurs mainly in the surface soil at the top of the slope.

(2) It will happen failure of landfill slope under natural filling condition. According to the deformation characteristics of the slope under the action of gravity and the actual situation of the project,it is decided to aggrandize the safety factor of slopeby setting geogrids in the filling body.

\section{References}

[1] Zuxian Chen, in: Stability analysis of soil slope: principle, method and procedure, China Water\&Power Press(2003) (In Chinese).

[2] Youcai Zhao. in: Domestic waste sanitary landfill technology, China Chemical Industry Press (2004) (In Chinese).

[3] Youcheng Gong. Waste Landfill Hazard Disposal Measures and the Application in the Engineering. Industrial Safety and Environmental Protection, 2008(34):9-11(In Chinese).

[4] Jiru Zhang. Finite Element Simulation And Stability Analysis On Slope Excavation. Chinese Journal of Rock Mechanics and Engineering, 2002,21(6):843-847(In Chinese).

[5] Aiguo Yao, M.Smith. Predicting the stability of the reforced slope with retaining wall. Coal Geology \& Exploration, 2003. 31(2):42-44(In Chinese).

[6] Fangpeng Cui, Ruilin Hu, Ming Zhang. Basic Characteristics And Formation Mechanism Of Col-Lapsed And Slided Debris Mass I Nduced By Xiaonanhai Earthquake In Chongqing City. Journal of Engineering Geology, 2009,17(2);167-174.(In Chinese).

[7] Zhaoran Xiao, in: Soil mechanics, p.114, Zhengzhou University Publisher(2007) (In Chinese). 